This PDF is a simplified version of the original article published in Internet Archaeology. Enlarged images and interactive features which support this publication can be found in the original version online. All links also go to the online version.

\title{
From Archive to GIS: Recovering Spatial Information for Tholos IV at the Palace of Nestor from the Notebooks of Lord William Taylour
}

\author{
Michael P.A. Loy, Sharon R. Stocker and Jack L. Davis
}

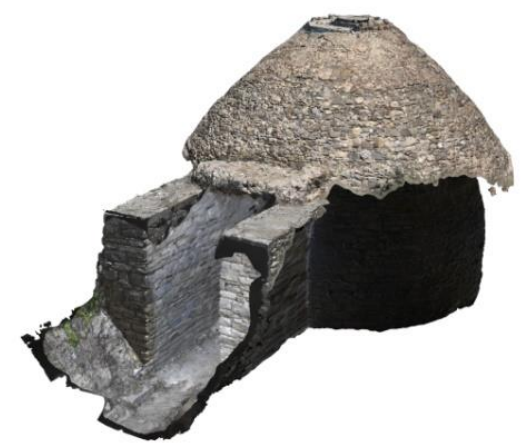

Oblique view of Tholos IV, Palace of Nestor

This article is a case study in doing new things with old data. In 1953 Lord William Taylour directed the excavation of a monumental vaulted tholos tomb known as 'Tholos IV' at the site of ancient Pylos, Messenia, Greece. The excavation was conducted over two months, during which detailed notes were recorded in three notebooks now kept in the Archives of the American School of Classical Studies at Athens. The formal publication of Tholos IV, however, contains only a basic narrative of the excavation, offering neither precise detail on stratigraphy, object find spots, nor even a complete inventory of small finds. The present study goes back to the original notebooks kept by Taylour and combines the data contained in them with a new digital survey of Tholos IV to produce a comprehensive and accurate 3D GIS model for the excavation.

Furthermore, the GIS has been produced in such a way that its dataset is compatible with new excavation data currently generated in the ongoing Palace of Nestor Excavations (PONEX) project, bringing together two excavation campaigns conducted under very different circumstances, methodologies, and recording protocols. Discussion follows on how the production of this GIS deepens our understanding not just of the legacy excavation, but also of the site and its wider landscape. 


\section{Archives and GIS: Digitisation vs Digitalisation}

Archaeological best practice recommends that research begins at the desk, in the library, or in an archive, assessing the current state of the art (Marvell 2014). In many cases this involves synthesising a range of legacy data into layers of a GIS (i.e. moving from an analogue to a digital format), allowing one to see links between datasets that are not so clear when viewed separately (e.g. May 2020). The requisite work is not simply an automatic process of digitisation, but requires the digitalising and coding of information into quantifiable and geospatial formats (Esteva et al. 2010; Clarke 2015; Wylie 2017; Richards-Rissetto and Landau 2019). For example, scanning a paper notebook to an image or PDF document is just the first step. That PDF needs to be postprocessed so that its constituent data become accessible: this might involve transcribing the notebook, or (in a process that requires close reading and critical decision making) translating or re-coding information into a different format, e.g. from a text narrative to a data table. It can even be a challenge to mesh together born-digital data, as file formats may be incompatible (Allison 2008a). Quite simply, archives contain centuries' worth of important archaeological information, but to unlock that information most effectively robust strategies of interpretation and close analysis are required. This article is a case study in moving from a set of analogue data repositories to an integrated digital GIS.

Many projects have already risen to the challenge of building GIS databases almost entirely from archival data. The results have been productive both for answering questions of archaeology (Allison 2008b; Witcher 2008; Woywitka and Beaudoin 2009; Mihai et al. 2020) and also those of cultural history (Heaton 2003; GonzálezTennant 2016). For the ancient Mediterranean, the principal focus of this article, substantial work has already been undertaken at Isthmia, where both the sequence of trenches has been digitised (Steele and Frey 2018) and all finds and spatial information recoverable from the notebooks of the 1970-1972 excavations (Ellis et al. 2008). The excavations from Ayia Irini on Cyprus have also yielded important results (Vassallo 2019), projecting in full 3D imagery trench locations and volumes as reconstructed from 1935 notebooks of the Swedish Cyprus Excavation. These examples, although few in number, demonstrate well the value that can be added by transforming archival data and, where possible, presenting them digitally alongside newly acquired born-digital data.

This article is a case study in using archive and legacy information to say new things about an old excavation. It focuses on ancient Pylos in Messenia, southern Greece, where in 1953 a monumental vaulted 'tholos' tomb was excavated: the documentation of the excavation was kept by Lord William Taylour and is now curated in the Archives of the American School of Classical Studies in Athens. Discussion will be offered on the challenges faced by interpreting the notebooks of Lord William Taylour for repackaging into a 3D GIS environment, and on the extent to which high-quality spatial information is recoverable. Furthermore, it will consider how this legacy information can be integrated into the GIS of the ongoing excavations at Pylos, making the data from an excavation conducted nearly seventy years ago broadly comparable with those of one conducted today. 


\section{Background and Rationale 2.1 PONEX project digital documentation}

The Palace of Nestor Excavations (PONEX) project began its campaign in 2015, sponsored by the University of Cincinnati and conducted under the aegis of the American School of Classical Studies at Athens (directors: Sharon R. Stocker and Jack L. Davis). The project aims to investigate the area immediately north-east of the Palace of Nestor on the Ano Englianos ridge, with a view to exploring domestic remains in the region (Figure 1).
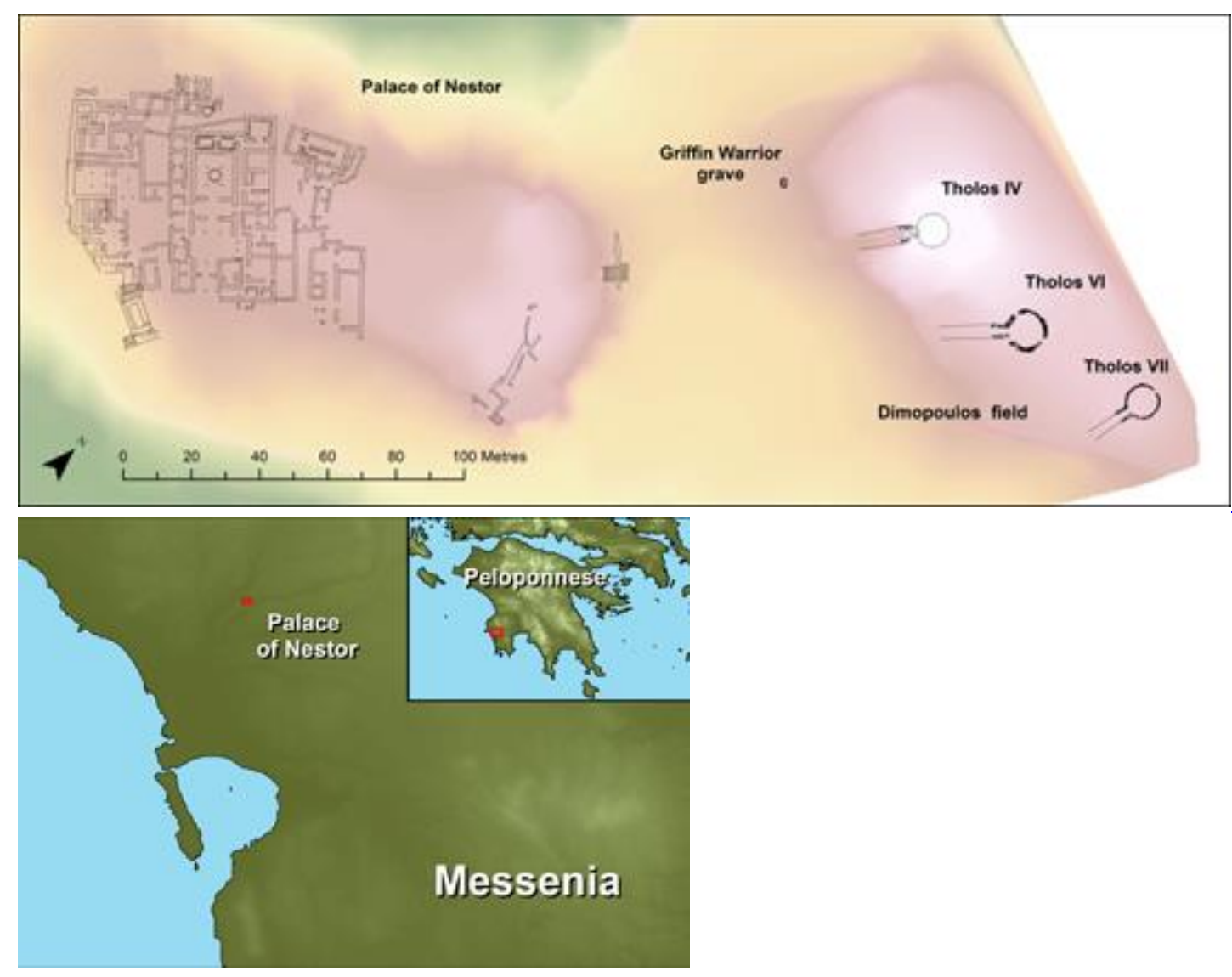

Figure 1: Location of Palace of Nestor, Messenia, in the Peloponnese of Greece.

Excavated architectural remains from the Palace, Griffin Warrior Grave and the two new Tholos tombs (known as Tholos VI and Tholos VII) are reproduced here in order to put Tholos IV into its wider site-level context.

Since the start of the project spatial point data in the field have been recorded via a Leica TS06plus total station, and all point data are accurate to $8 \mathrm{~mm}$. The total station is connected via a GEV267 to a tablet laptop running the data collection software EDMWIN (Dibble and McPherron 2010). Thereafter, point spatial data and metadata are saved immediately to a Microsoft Access database file to be uploaded to a Filemaker database upon returning from the field every day. This is the main project database that holds all other excavation, conservation, and multimedia information. As is required, point and level information is downloaded from the Filemaker database for manipulation in the GIS, where the geodatabase of the project exists separately. 
Since 2018, the project began a routine of regularly documenting trench excavation through photogrammetry, using Agisoft Photoscan to process sets of DSLR photographs shot in the field. This documentation proved especially timely: in 2018 , upon purchasing and starting to explore a new area to the north-east of previous excavations (a plateau hilltop formerly owned by the Dimopoulos family), two new tholos tombs were discovered - monumental stone-lined circular tombs that would once have had vaulted roofs. Regular photogrammetric recording of both structures was undertaken during their excavation, in order to assist in the documentation and interpretation of such complex structures. From 2019, a more regular programme of photogrammetry for each structure and each trench was devised.

Through the combination of regularly produced photogrammetric models and accurate recording of point data, it is possible for the project as part of the normal workflow to produce distribution maps for all excavation finds projected against the latest 3D models of the excavation.

\subsection{Restudy of Tholos IV}

The newly discovered tholos tombs lie east of a previously known tomb, excavated in 1953 by Lord William Taylour (Taylour 1973). This was known as the 'Kanakares tomb' to Taylour (named after Mr and Mrs Panayotis Kanakares, who owned the land on which the tomb was located), and 'Tholos IV' to the director of the Palace of Nestor excavations, Carl Blegen-1. The present excavations at the Palace of Nestor continue to use and build on Blegen's classification, referring to the two most recently discovered tombs as Tholos VI and Tholos VII. And so, for consistency with the ongoing project, the subject of Taylour's excavations is referred to in the present article as 'Tholos IV' (Figure 2).

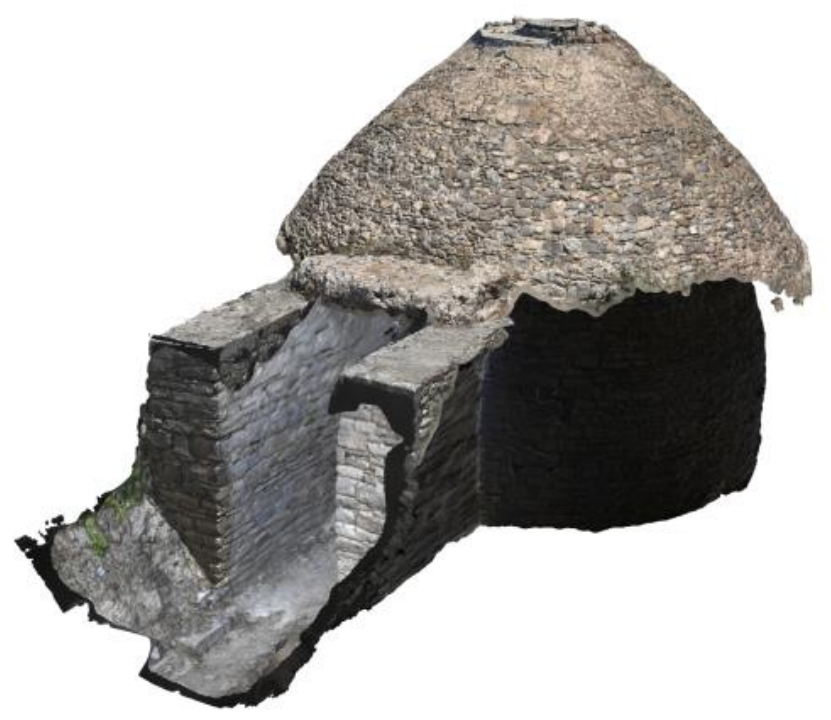

Figure 2: Oblique view of Tholos IV, Palace of Nestor. This photogrammetry model is synthesised from four separate models (chamber, antas, lintel stone, and domed roof exterior) and is georectified using both GPS-referenced control points and locallyreferenced common anchor points. 
Tholos IV, Palace of Nestor. 3D model of the 1957 reconstructed tomb. This photogrammetry model is synthesised from four separate models (chamber, antas, lintel stone, and domed roof exterior).

Excavation of the tomb began on 25 May 1953, directed by Taylour and undertaken by four workmen. The narrative that follows here is an abridged account of that given by Taylour (1973, 98-107). Work began in the area of the tomb's lintel block (visible above ground), working first on the outside and then the inside of the blocking wall in the structure's doorway. The dromos (entrance corridor) of the tomb extended across the Kanakares' vineyards, and permission was only granted to dig here from half-way through the campaign. Meanwhile, the interior of the tomb was dug in two sections, separated artificially by a staircase formed to allow workmen to access the interior space (Figure 3). The floor of the tomb was found $4.9 \mathrm{~m}$ down from the surface, revealing a structure with a total diameter of $9.35 \mathrm{~m}$. Excavation continued a further $1 \mathrm{~m}$ to investigate pits dug into the tomb floor, in addition to the excavation of a stone cist found by the south-east wall. Excavation ended on 23 July, 51 days after the first trench was opened.

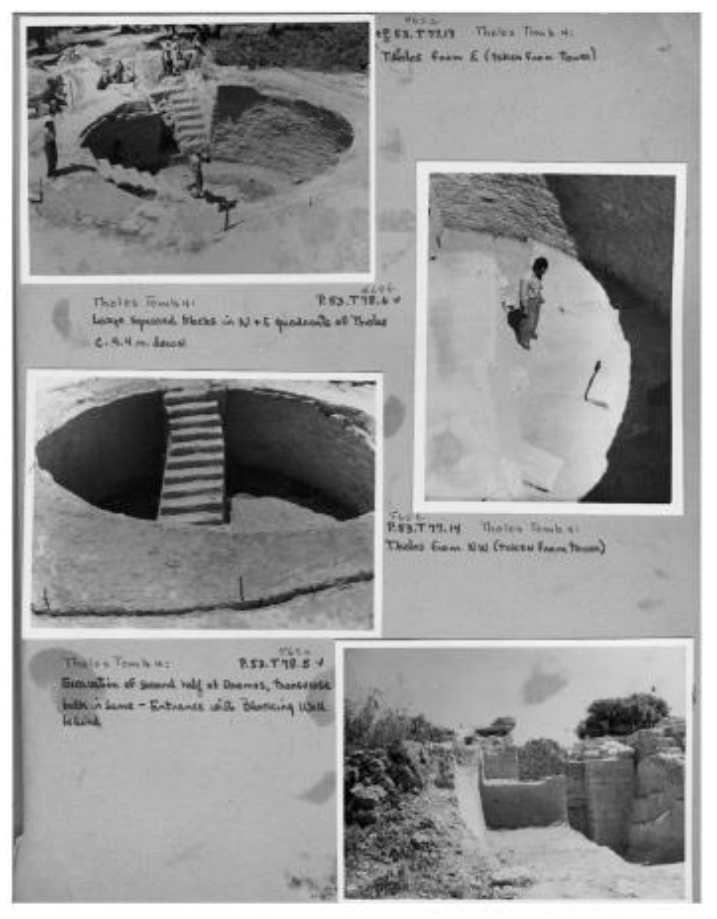

Figure 3: Photographs of the excavation of Tholos IV, from ASCSA Archives, Pylos Excavations Archive, Box 8, 'Pylos 1952-1953'. From the top, the first and third photographs illustrate the construction of an artificial staircase used by the excavators to access the tomb's chamber. The second photograph shows the division of the chamber into two sectors, and the bottom photograph shows the clearing of the dromos in front of the stomion.

The tomb was subsequently reconstructed by the Greek Archaeological Service in 1957 (ASCSA Archives, Pylos Excavations Archive, Box 2, 'Pylos 1957 CWB: with loose notes in pocket', p.134). Sadly, there is no documentation of the reconstruction process, 
save for a passing note that Blegen makes in the papers referenced above. The most obvious part of the reconstruction was the rebuilding of the domed roof, whose original structure had been discovered in a collapsed form during the excavation. Comparing archival photographs to the monument as can be visited today, it is also clear that repairs were made to the antas (doorjambs) of the stomion (doorway), particularly to the south anta (Figure 4).
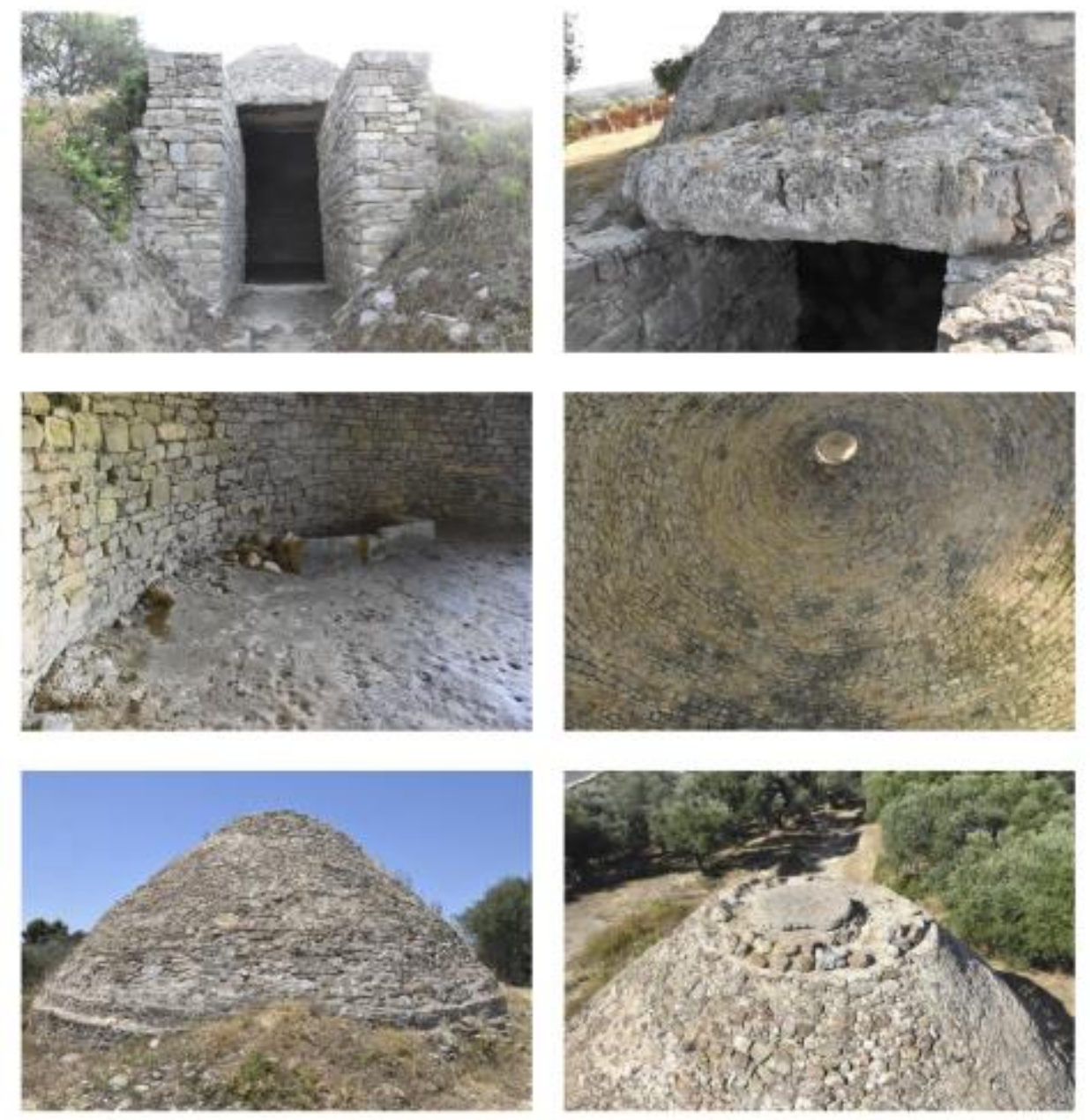

Figure 4: Photographs taken during the production of the photogrammetric model that illustrate the current state of the Tholos IV reconstruction. From left-to-right, the first two images show the stomion and lintel block of the tomb, indicating also that the tomb is built into the side of the hill. The third and fourth images show the inside of the tomb, and respectively illustrate the walled cist grave and the modern reconstructed capstone on the domed roof. The fifth and sixth pictures show the state of the domed roof from the exterior, the sixth picture also showing the extent of the dromos.

As part of the 2020 PONEX summer field season, the directors initiated a restudy of the Tholos IV. The aim of this project was to create a digital documentation of the structure compatible with ongoing documentation of the 'new' Tholos VI and Tholos VII, recovering as much spatial information as possible about the stratigraphy and finds. This work took place over two week-long sessions (22-26 June and 7-14 July 2020), and drew data from four primary datasets: 
i. Volume III of The Palace of Nestor at Pylos in Western Messenia, edited by Carl Blegen and Marion Rawson. This volume contains both a narrative description of the excavation and finds of Tholos IV (Taylour 1973) and six architectural plans of the tomb (Blegen and Rawson 1973, figs 321-6), prepared by Demetrios Theocharis.

ii. One photograph album covering excavations at the site between 1952-1953, from the American School of Classical Studies at Athens Archives, Pylos Excavations Archive (ASCSA Archives, Pylos Excavations Archive, Box 8, 'Pylos 1952-1953'). Fifty-eight of the photographs in this album document the excavation of Tholos IV, covering the entire period of the excavation 25 May-23 July.

iii. Three excavation notebooks kept by Lord William Taylour during the excavation, from the American School of Classical Studies at Athens Archives, Pylos Excavations Archive (ASCSA Archives, Pylos 'Excavations Archive, Box 1, 'Pylos 1953 WDT Kanakares, part I', 'Pylos 1953 WDT Kanakares, part II' and 'Pylos 1953 WDT Kanakares, part III'). These notebooks contain a narrative of the excavation, a series of sketchplans, and an inventory of small finds (Figure 5).

iv. Spatial data captured through topographic and photogrammetric survey, conducted by the authors in June and July 2020. More detailed information on this procedure is given immediately below.

Figure 5: Scans from the notebooks of Lord William Taylour (ASCSA Archives, Pylos Excavations Archive, Box 1, 'Pylos 1953 WDT Kanakares, part l', 'Pylos 1953 WDT Kanakares, part II' and 'Pylos 1953 WDT Kanakares, part III'), indicative of his recording style. Figure 5a shows his itemised running list of finds with page number crossreferences; Figure 5b illustrates a technical sketch during the laying out of the first trenches across the top of the chamber, with facing narrative description; Figure $5 \mathrm{c}$ shows a sketch of the grid-plan used during the excavation of the final levels of the chamber, with some description of objects found.

Figure 5 ONLINE SLIDESHOW

As will become apparent below, the most important datasets for this project were the notebooks (iii) and the newly surveyed spatial data (iv); the other two data sources were important mainly for verifying and clarifying information found in the notebooks.

\section{Methodology \\ 3.1 Photogrammetric survey}

The exterior and interior of Tholos IV were documented between 23 and 26 June, according to the standard protocols devised by the team during the excavation of Tholos VI and Tholos VII. Photographs of the structure were shot using a Nikon D5600 DSLR in four separate phases, allowing time to roughly process and check the quality of models generated between each set. These four sets comprised the chamber interior and stomion antas (side faces), the stomion antas (top faces) and lintel block; the exterior of the chamber roof; and the top and capstone of the exterior chamber roof. The use of a 
monopod and remote shooting (using the app Nikon SnapBridge) was necessary to complete the first and fourth set of photographs.

Each set of photographs was rendered as a separate 'chunk' in Agisoft Photoscan using the following settings:

- Cameras aligned with medium accuracy, generic preselection, key point limit 100,000, tie point limit 0

- Image masks were used with at least five common reference points tagged in each chunk

- Dense cloud was rendered in low quality with aggressive depth filtering

- 3D model was built with arbitrary surface type, interpolation enabled, low quality, depth filtering aggressive

- Texture mapping was completed on generic settings, blending mode, with mosaic selected. Texture size: $25,000 \times 25,000$; hole filling enabled and no ghost filtering

Through experimentation between the 2018 and 2020 PONEX field seasons during the excavation of Tholos VI and Tholos VII, these settings were found to provide the optimal balance between quality of models produced and speed of production (given the hardware available at the PONEX study centre) such that large structure photogrammetry could be regularly processed and its spatial data made available to the field data.

Georectification was possible for all four photogrammetric chunks. Datum control points had been set across the site in 2015 and in 2017 using a DGPS: three were close enough to Tholos IV such that a Leica total station could be set up in the dromos leading to the tomb, allowing a series of accurate ground control points to be recorded for the interior and exterior of the chamber and stomion. For the exterior of the chamber roof, the total station was set up in the Dimopoulos field (i.e. in its usual position to survey the excavation of Tholos VI) where, from an elevation roughly level with the roof of Tholos IV, a series of control points were shot with the total station in reflectorless mode. Such was sufficient to georectify each separate chunk. The merging of the four chunks was aided by locating common 'link stones' between each model, and using the 'measure' tool within Photoscan to locate their coordinates.

A GeoTIF of the tholos floor was exported for use in ArcMap, and a COLLADA 3D model (.dae) was exported to ArcScene. The coordinate system was set to WGS 84/UTM zone 34N (EPSG::32634), with an export texture JPEG and precision factor of 6.

\subsection{Trench locations}

The PONEX project stores spatial information for all excavation levels in a geospatial database using ArcMap (i.e. extent and elevation). The goal with Tholos IV, therefore, was to reconstruct the extent and elevation of Taylour's excavation units and to store this information in a comparable format.

Using the GeoTIF exported from the above photogrammetry model, it was possible to georectify the accurate technical sketches made by Theochares and published in the Blegen and Rawson volume (1973). Tracing from these sketches, five pits (the remains of which are no longer visible) found during the excavation were located in GIS (Figure 
6). The walled cist grave found in the south-east part of the tomb during excavation was traced directly from the GeoTIF.

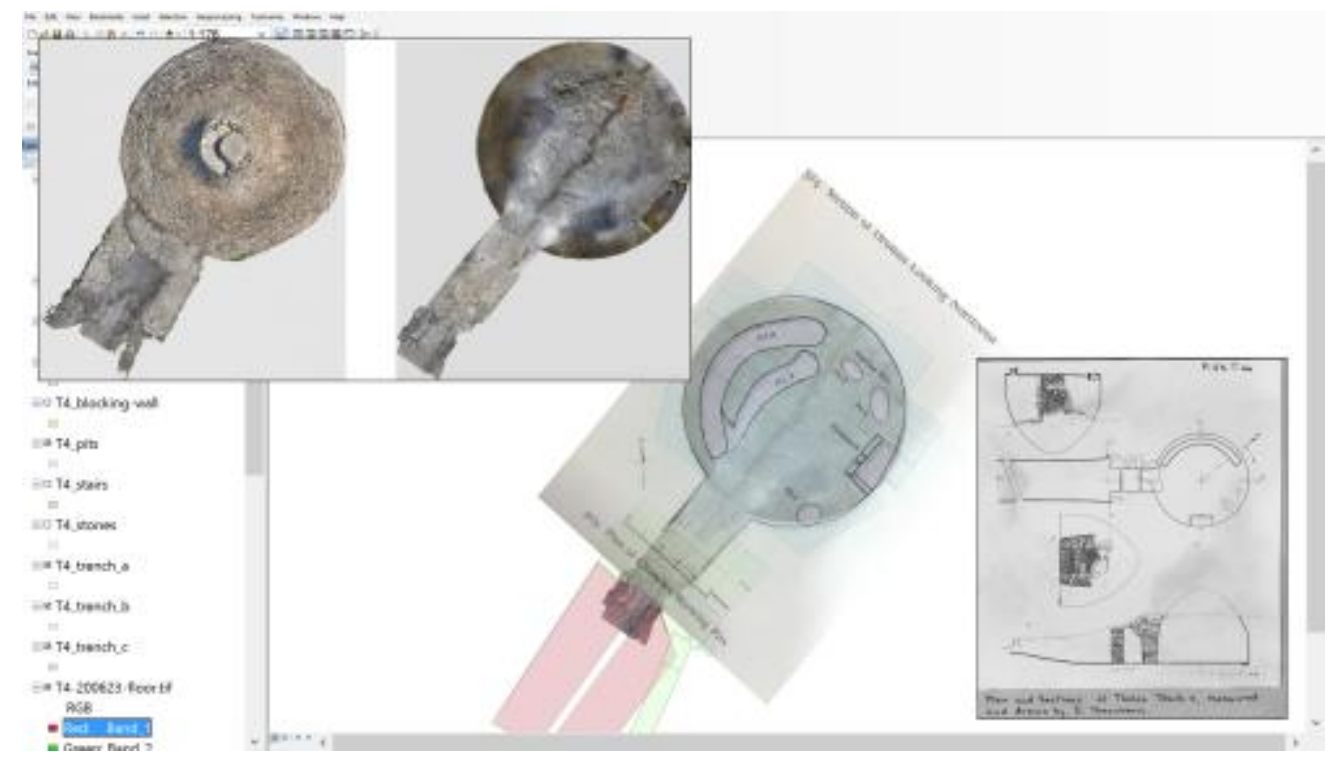

Figure 6: GIS workspace, indicating the overlay of Demetrios Theocharis' architectural plans with the photogrammetry TIF export of the Tholos IV floor. Superimposed to the top left are the top-down images of the tholos as exported from ArcSoft Photoscan, indicating that the floorplan is a 'slice' taken out of the georectified model. Superimposed to the bottom right is another plan and section by Theocharis, showing the level of technical information available for this excavation.

Apart from these 'ground features', it was more complex to locate the area covered by each of Taylour's trenches. Taylour's notes contain narrative descriptions for all trenches and excavation units; sketches, however (not drawn to scale, but containing in some instances measurements of length and width), were made of only some trenches. Where it was possible to find points in common between the sketches and the GeoTIF, sketches were scanned and georectified, but (owing to the nature of these sketches as not-to-scale) this was done only to locate the general area of a trench - not for direct tracing. Using these sketches as a rough guide to place and orientation, and combining this information with the measurements recorded by Taylour, it was possible to locate in the $X Y$ direction (with some degree of accuracy) all 31 trenches opened in the chamber, stomion and dromos (Figure 7). 


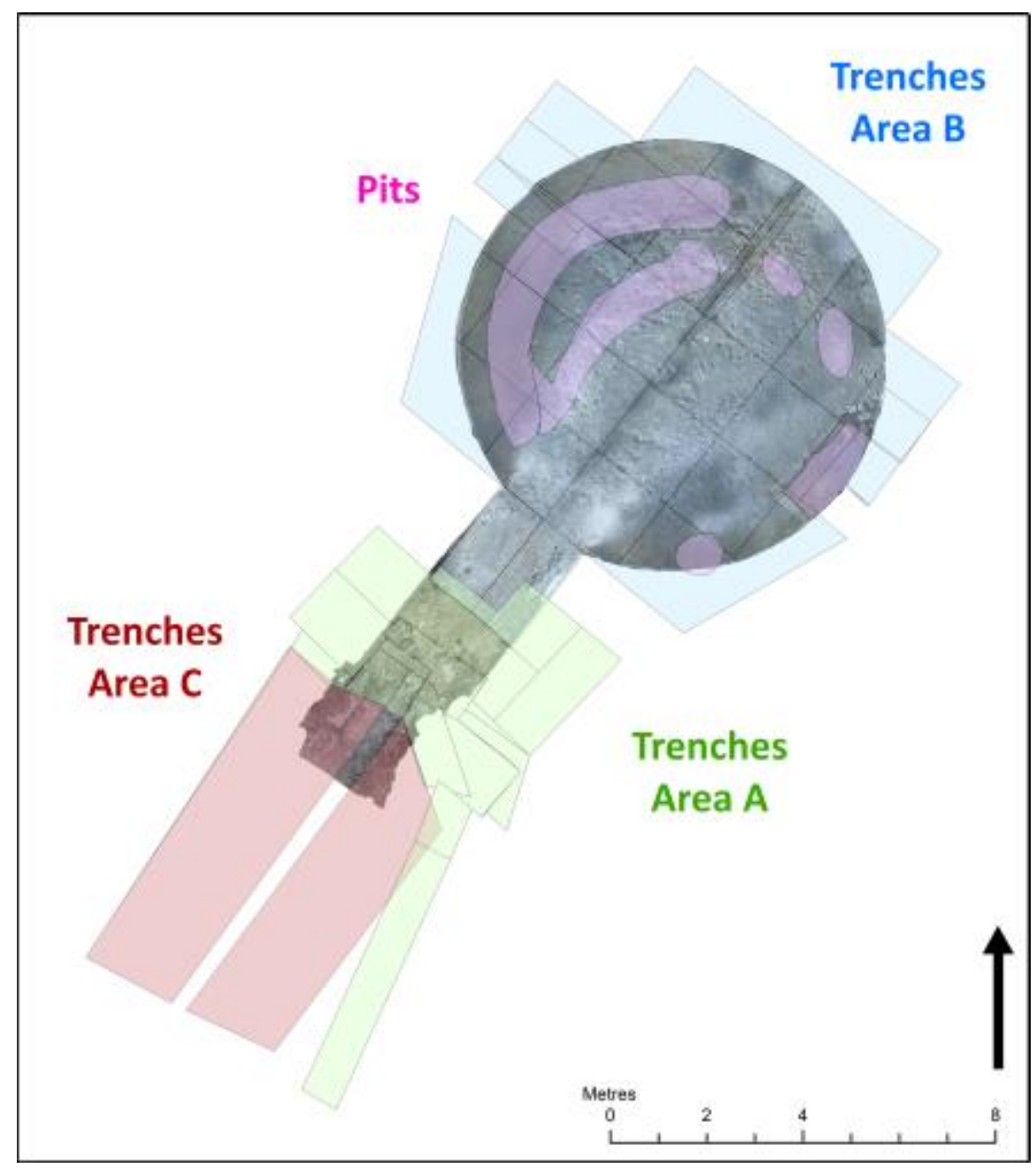

Figure 7: Trench locations, superimposed on the photogrammetry TIF export of the Tholos IV floor. ' $A$ ' trenches were opened around the stomion, while ' $B$ ' trenches cover the chamber. Trenches in these two areas were opened almost simultaneously, whereas the dromos trenches in area ' $C$ ' could only be opened late in the campaign owing to the need to obtain permissions from the landowner.

Within the 31 trenches, Taylour distinguishes 125 separate excavation levels. A stratigraphical sequence was drafted from his notes. In most cases, excavation levels in the chamber area directly overlay one another and the sequencing was relatively simple. The photograph collection also helped to clarify the order in which certain parts of the tomb were excavated, as did the publication by Blegen and Rawson (1973). Taylour's notes are relatively opaque, in particular on when trench baulks were removed; the chronology for which can be reconstructed by cross-referencing photograph dates in the album with dated notebook entries.

\subsection{Stratigraphy - relative and absolute}

Neither the Taylour notebooks nor the Blegen and Rawson (1973) publication contain any absolute elevation data for Tholos IV. Taylour did, however, note the elevation of his level start points relative to certain fixed points of the excavation, e.g. level B(c)-10 is recorded as being ' $4.05 \mathrm{~m}$ beneath the $\mathrm{N}$ (NW) vault' (p.159), level C2-6 was '1.5m above the stereo' (p.102). Moreover, Taylour's digging technique was quite consistent, 
and allows for the size of various excavation levels to be reliably estimated. For the final $1 \mathrm{~m}$ of the excavation above the floor level inside the chamber (and within the pits located inside the chamber area), Taylour chose to excavate in $10 \mathrm{~cm}$ spits, and so levels $10-19$ of trenches $B$ and $B(c)$ were understood to have had $0.1 \mathrm{~m}$ absolute spacing between.
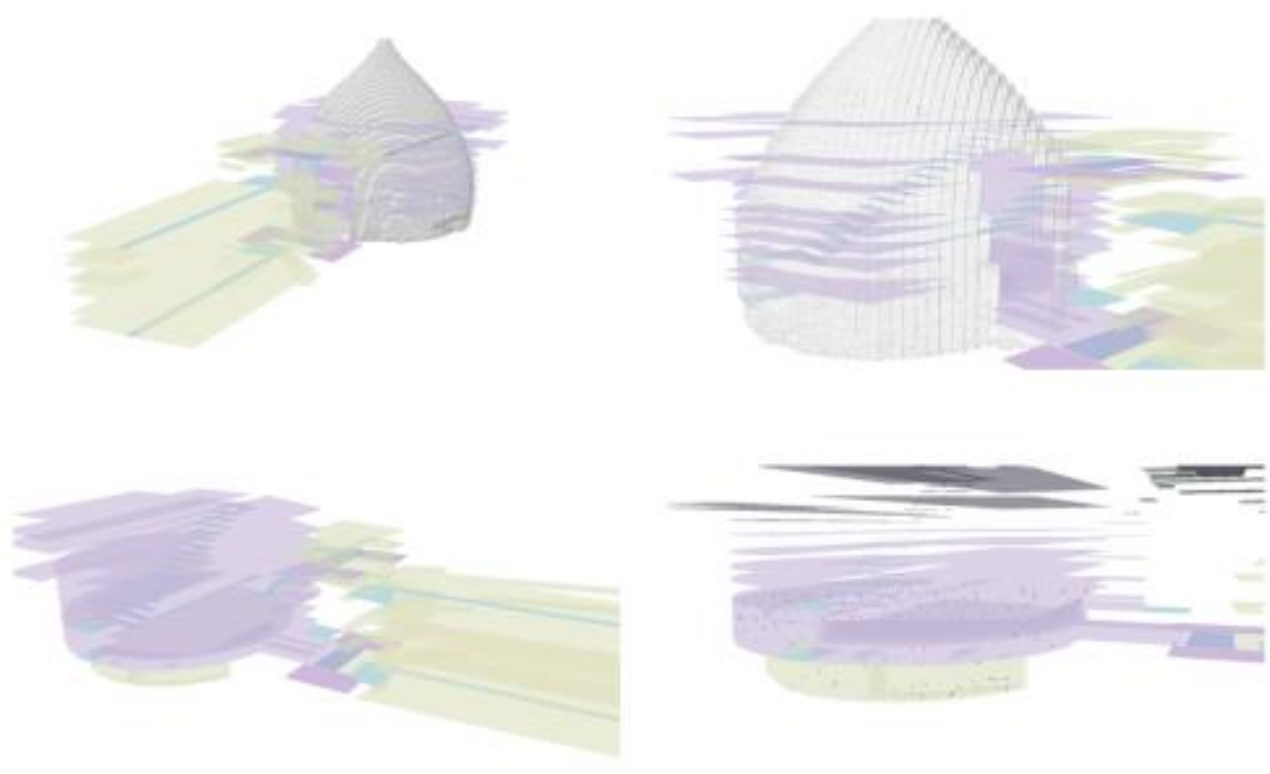

Figure 8: Screenshots taken from ArcScene showing the 3d reconstruction of levels and finds. Going clockwise and starting in the top left, the first and second images include a transparent overlay of the chamber, exported from Photoscan as a COLLADA file. The bottom left image shows the levels with absolute elevation values assigned, while the bottom right image also indicates the distribution of amber (yellow points), amethyst (red points) and gold (blue points) throughout the excavation.

Taking all of these descriptions into account, it was possible to assign relative elevation values to all 125 excavation levels, such that the 2D ArcMap model could be visualised in 3D when moved into ArcScene (Figure 8). Clearly, though, the stratigraphic excavation did not take place in exclusively horizontal levels, and it is a simplification to record only one elevation per unit?

Through the identification of two 'fixed' points - points that were described in the notebook whose coordinates were located using the 'measure' tool of Photoscan on the Tholos IV photogrammetric model - these relative elevation values were transformed into absolute elevation values above sea level. These two points (one from the lower levels of the excavation and one from near the top) represented the floor level of the chamber ${ }^{3}$, and the top level of the north anta. The south anta was found in a fragmentary state by Taylour and so its current elevation represents the post-1957 repair level, not its elevation during the 1953 excavation. While the accuracy of the transformation between relative and absolute stratigraphic levels could be improved by having a greater number of tie points, this is complicated by the 1957 reconstruction, without detailed documentation for which it is hard to verify how the structure might have been altered since it was first excavated. 


\subsection{Small finds}

Taylour's notebook contains an inventory of 298 small finds. Many of these numbers refer to multiple items, in addition to which unnumbered and bulk finds are described. Some 840 separate objects can therefore be catalogued in a restudy of this inventory, for which XY spatial information is available for 587 finds (c. $70 \%)$.

Three methods were used for locating spatial information. First (and providing the greatest degree of accuracy) were the sketch maps drawn by Taylour. For the final ten levels of the excavation in the chamber, Taylour excavated in grid squares of c. $1.8 \times$ $1.8 \mathrm{~m}(c .6 \mathrm{ft} \times 6 \mathrm{ft})$ : sketches of the grid layout were georectified to the floor GeoTIF, onto which the sketched find locations were transferred. Second, some finds were described generally (although often quite precisely) in the narrative, e.g. ' $1.75 \mathrm{~m} \mathrm{~N}$ of the doorway' for find no. 50, bronze fragments (p.81). These points were plotted into the GIS fitting as closely as possible to the descriptions given. Third (and least accurate) one had to deal with cases where only a trench and level number were recorded, i.e. there was no further indication within a level where the relevant object was found. For these objects, the 'random point' tool of ArcMap was used to locate a point within the bounds of the relevant trench. Clearly, for smaller trenches there is likely to be a smaller degree of error between the random point assigned and the 'true' point. Thankfully, most of the objects assigned in this way (and indeed most of the finds from the excavation) came from lower levels of the excavation in which Taylour was digging by grid squares (i.e. in relatively small spatial units), and so the total error introduced to the GIS by this procedure is relatively small. Moreover, even using this third and least precise method of spatial reconstruction, the average error of all points plotted in the Tholos IV project is estimated to be $0.2 \mathrm{~m}$ in radius from the point plotted.

In very few cases the notebooks indicate at what point within an excavation level an object was found. Where no other information was available, the Z-height from which a find originated was taken to be equal to the elevation of the level with which that object was associated. Assigning values for all possible finds in this way allowed for the projection in 3D of all findspot points. This is the sort of model that is produced routinely in the ongoing PONEX project for Tholos VI and Tholos VII (through the linking of the project database to the $2 \mathrm{D}$ and $3 \mathrm{D}$ GIS), thus providing a comparative visualisation for both the legacy and the contemporary excavations.

\subsection{Post-processing and archiving the data}

Before archiving the geospatial data, it is necessary to reflect critically both on their nature and, in particular, on the accuracy of any information derived from them. It has already been noted that there are inaccuracies within the excavation notebooks.

Taylour's trench diagrams are sketches which - although often labelled with dimensions and measurements 4 - require interpretation to map them to absolute $X Y$ locations. Taylour's narrative descriptions help, but much of the translation from notebook to GIS was in this case a subjective and interpretative process. Furthermore, one must also bear in mind that the precision of any measurements Taylour discusses is usually only precise to $0.1 \mathrm{~m}$ or $0.05 \mathrm{~m}$ (vs the millimetre precision of a total station). Next, there is the issue of the 'missing' information. The most crucial missing step in using the new digital survey to map the trench notebooks is in not knowing precisely how the tholos reconstruction as seen at the site of the Palace of Nestor today relates to the 
structure when it was first excavated. Excavation photographs (i.e. from before the 1957 reconstruction) are helpful for clarifying some basic information. But they are in fact too few, taken too sporadically throughout the excavation, and too selective in what information they show to clarify all questions raised by this project ${ }^{-}$. The other aspect concerning missing information is in the process of allocating random points within trench levels to geolocate small finds for which we possess no finer spatial information. This issue has been discussed more extensively above. And then there are necessarily programme errors generated in processing the data (for example, ArcSoft Photoscan reports that in the generation of the Tholos IV chamber model there is potential for an error up to $0.059 \mathrm{~m}$ ), the sort of error that is amplified every time we move to another piece of software and which can be reduced by keeping the methodology as streamlined and tight as possible. Bearing all of these errors in mind, the authors estimate that in the final generation of small find coordinates, the average error is $0.2 \mathrm{~m}$ between the calculated location and the potential 'true' location of a find. This rises to $0.7 \mathrm{~m}$ when finds must be located within much larger trench level units.

How does this level of accuracy compare to the GIS of the current excavations of the PONEX project? As noted above, the maximum error acceptable in the field when recording spatial information with the total station is $8 \mathrm{~mm}$, and all trench levels are mapped accurately with surveying equipment. Some equipment and programme errors will still enter the dataset in a random way as discussed above - but this does not compound the total error for each point or level measured beyond a few centimetres at best. The exception to this sort of precision is in the plotting of points for small finds that are obtained through wet sieving. In this case, during the excavation soil is collected for the wet sieve in 'buckets'; 'buckets' have recorded for them a single central coordinate, around which soil was collected within a radius of $c .0 .15 \mathrm{~m}$; all soil collected is water sieved, so any small finds located in the sieves can be placed spatially within this approximate bucket area. In comparing this level of accuracy to that of the finds of Tholos IV, one sees here that the 'coarsest' level of data generated in the current PONEX excavations $(0.15 \mathrm{~m}$ radius) is somewhat equivalent to the 'best' quality of data recoverable from Lord William Taylour $(0.2 \mathrm{~m}$ radius). When it comes to analysing these two datasets side by side, it will be important to 'buffer' those different radii of accuracy around any point data plotted.

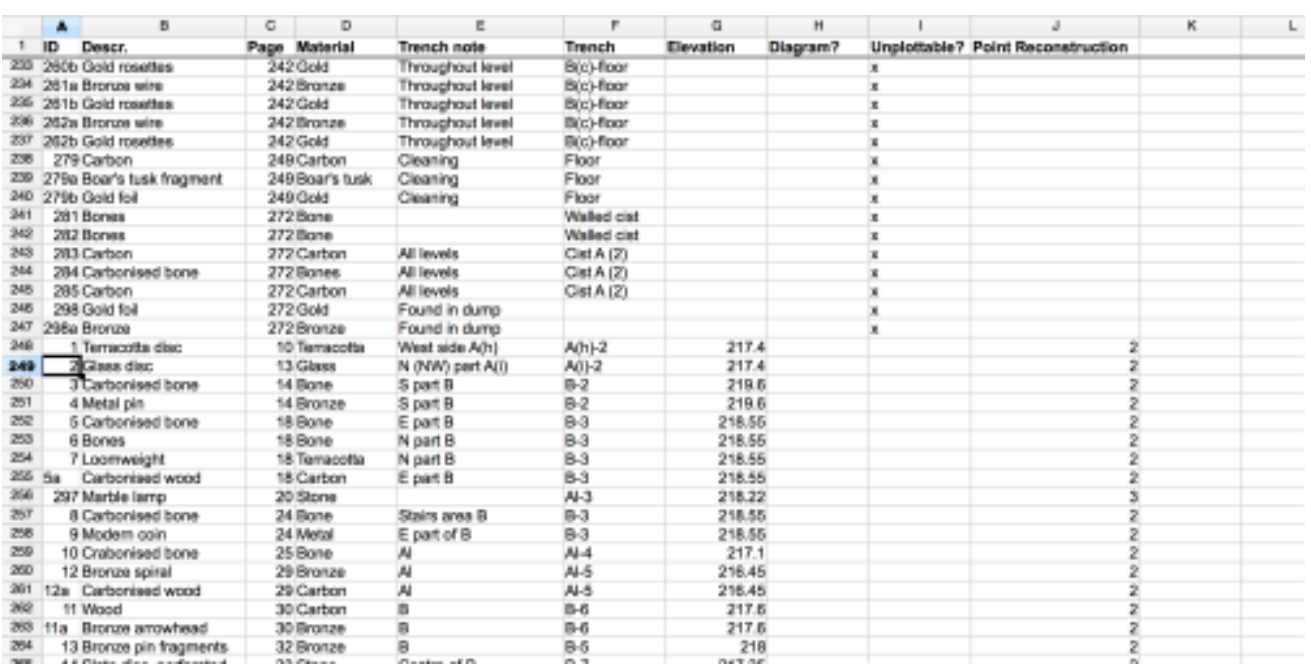

Figure 9: Screenshot from a CSV printout of the Tholos IV data of small finds, extracted from attribute tables linked to GIS layers. The method of findspot location reconstruction is recorded as a column of metadata, on a three-point system. Objects tagged ' 1 ' were 
located using sketches of the trench layouts; objects tagged ' 2 ' were located on the basis of general descriptions from the text narratives; objects tagged ' 3 ' were placed at random locations within the trench-level extents.

In terms of archiving, the Tholos IV spatial work is already integrated with the GIS of Tholos VI and Tholos VII. Point and level shapefiles are stored in a common geodatabase (and the photogrammetry models are saved in a common archive), wherein information on artefact types, unique identifiers and elevation data is stored in the form of attribute tables attached to these GIS layers (Figure 9). These attribute tables preserve original IDs and trench labels as assigned by Taylour, and they crossreference information back to page references of his notebooks. The PONEX geodatabase does not currently link with the relational excavation database curated in Filemaker, and so - as the priority for this current work was to extract spatial information from the Taylour notebooks, not to create a comprehensive database of every aspect of the excavation - more detailed object data concerning artefact descriptions, dimensions, notes on the stratigraphy etc., have yet to be migrated from the Taylour notebooks to the Filemaker dataset. Further work will enter the full Tholos IV excavation into the PONEX database.

Finally, as has been made evident above, during this project a number of interpretative decisions were taken in processing and digitalising the notebook data. These decisions have been (and will be) recorded in various ways. In the first instance, for internal use all PONEX digital methodologies and decisions are logged in a web-based forum 'Basecamp', a platform useful both for discussions on, and development of, procedure, and for reporting on work completed. Second, some of these interpretative decisions have been hardcoded into the GIS, with attribute fields attached to point and polygon layerfiles distinguishing between original or calculated coordinate values (and also assigning the method of coordinate calculation to a bin category, as seen in Figure 9); in handling the spatial data, this allows one to analyse differently sets of points derived in different ways (e.g. those that have been derived through random-point allocation within trench layers can be given larger buffer radii during any heatmap analysis). All GIS layerfiles are also cross-referenced back to pages in Taylour's notebooks via a reference field in their attribute tables. Third and finally, discussions are still ongoing about how this information will appear in the final project publication, and about how and in what formats the digital data will be archived at the University of Cincinnati and at the American School of Classical Studies at Athens. Work on the PONEX project and its publication is in progress.

\section{Discussion}

This digital restudy of Tholos IV not only improves access to high-quality spatial information, but it also helps improve our understanding of the site and landscape in a wider context. This section outlines, via a few select examples, some instances where the Tholos IV GIS database has already been useful for assisting research, and also outlines further prospects.

First, the model improves on the accuracy of published spatial information. In The Palace of Nestor at Pylos in Western Messenia, 23 pages are dedicated to detailing a selection of the (most aesthetic) finds from the Tholos IV excavations: they are described typologically, dimensions are given, and relevant museum catalogue numbers 
are printed where finds were relocated for public display (most often to the National Archaeological Museum in Athens). The narrative discussion of the excavation (98-107) contains some basic information concerning the location of some finds (e.g. during the dromos excavation: '[a]n occasional tiny fragment of gold leaf was found at lower levels (at $1.45 \mathrm{~m}, 1.30 \mathrm{~m}, 1.20 \mathrm{~m}, 0.80 \mathrm{~m}, 0.20 \mathrm{~m}$, above stereo - measurements from the northeast end of the dromos) [100]'), but both precise absolute elevation data and XY location data are absent. Moreover, field inventory numbers are not included (nor even a precise count of objects found at each elevation) and so it is possible to obtain at best only a general sense of the distribution of finds. Most striking, it is difficult to locate where even the gold signet ring (NM7985) came from, described generally '...the stone cist that was built against the southeast wall...[the ring was] found near the stereo at the northeast end of the cist' (105). Taylour's notebook gives more information, indicating that the cist was dug in seven layers $(10 \mathrm{~cm}$ spits) and clarifying that the signet ring was found within the seventh level. Taylour even gives a grid square location for the ring. It is clear that there is a deficiency in the spatial information moving between the notebook and the final publication: the Tholos IV GIS helps to make that information more immediately available without having to trawl through the notebooks every time a reference is required.

Second, the Tholos IV GIS can be used to clarify and develop the archaeological narrative concerning the collapse and afterlife of the tomb. Taylour offers an interpretation of the sub-floor pits in the tomb, noting that they were likely dug by looters (Taylour 1973, 108-9). The distribution of object points around all three of the smaller pits would certainly support this hypothesis: halos and mounds densely concentrated with finds located around pits were likely created through the shovelling activity of looters disturbing and redistributing finds. By contrast, for the south-west side of the long pit ('Pit $A^{\prime}$ on Figure 6) and the walled cist pit, most of the finds recovered in these areas came from their floors. Of the finds recovered from the floor level of the tomb (Taylour's 'stereo'), most were found in the centre of the chamber and in parts closest to the stomion. There is a possibility that these areas of the tomb went relatively undisturbed by the looters. Crucially, these are details of object distribution that are difficult to eyeball in from the published notes or even from the notebook narrative alone, while the 3D GIS makes these distributions clear to see. One tool that might help to clarify these episodes of disturbance, however, will be the ability to bring in to the GIS the georectified sections drawn by Theocharis, mapping the arbitrary levels and spits dug by Taylour with the archaeological identified sequence 6 .

Third, as a research tool, the Tholos IV model makes readily available in a clear and interactive format this complex stratigraphical sequence that can be combined with other datasets. For example, all 53 bone points identified from Taylour's notes have been tagged with their small find inventory numbers, common with the labels on the human remains bagged and stored in the National Archaeological Museum?. Although, as is the case with other types of small find, the 53 bone points represents only a percentage of the total number of bone elements excavated (101), the GIS database can communicate with studies previously conducted on this material: the Tholos IV bones were studied most recently by Lynne Schepartz and Sari Miller-Antonio (Schepartz et al. 2009; 2011; 2017), providing both identification and an estimate of minimum number of individuals for the entire assemblage. Linking of the data to the 3D model allows us to see for the first time the distribution of bones in both XY- and Z-space (and the possible spatial verification of individuals) and the association of bones with small find objects, both within the same levels but also in adjacent stratigraphical units. Similarly, the 
pottery from the excavation is catalogued and, following further study, it will be possible to plug the chronological and phasing information straight into the Tholos IV model.

Fourth, at the level of the site, this model gives further contextual information on the funerary landscape surrounding the Palace of Nestor. As noted above, the Tholos IV GIS database has been designed to be compatible with that of the ongoing excavations of Tholos VI and Tholos VII, and the level of accuracy of the point data in Tholos IV is roughly equivalent to the lower-grain finds distribution data of the current project. This will allow for the same exploratory models and analyses to be run across the data of all three tombs, comparing horizontal and vertical distribution and concentration of key artefact types, thus helping to compare similarities and differences between use and destruction episodes of roughly contemporaneous structures. Merely as an example, in the ongoing PONEX project, heat maps are produced regularly to track the distribution and density of various object types. Analysis in the same form can be produced easily for Tholos IV. Similarly, here a heat map was generated for the distribution of 109 bronze artefacts (found between elevations 219.6m-214.7m), using ArcMap's Kernel density tool (spatial analyst toolbox, density toolset), with a radius defined of 0.7 (Figure 10 ). Bringing together data from across the Palace of Nestor site in this way will be a very powerful tool in writing the history of ancient Pylos as a whole: although decades may separate excavation and excavation methodologies, the various structures of the ancient site once existed together and they are most usefully visualised in a way that recreates their contemporaneity.

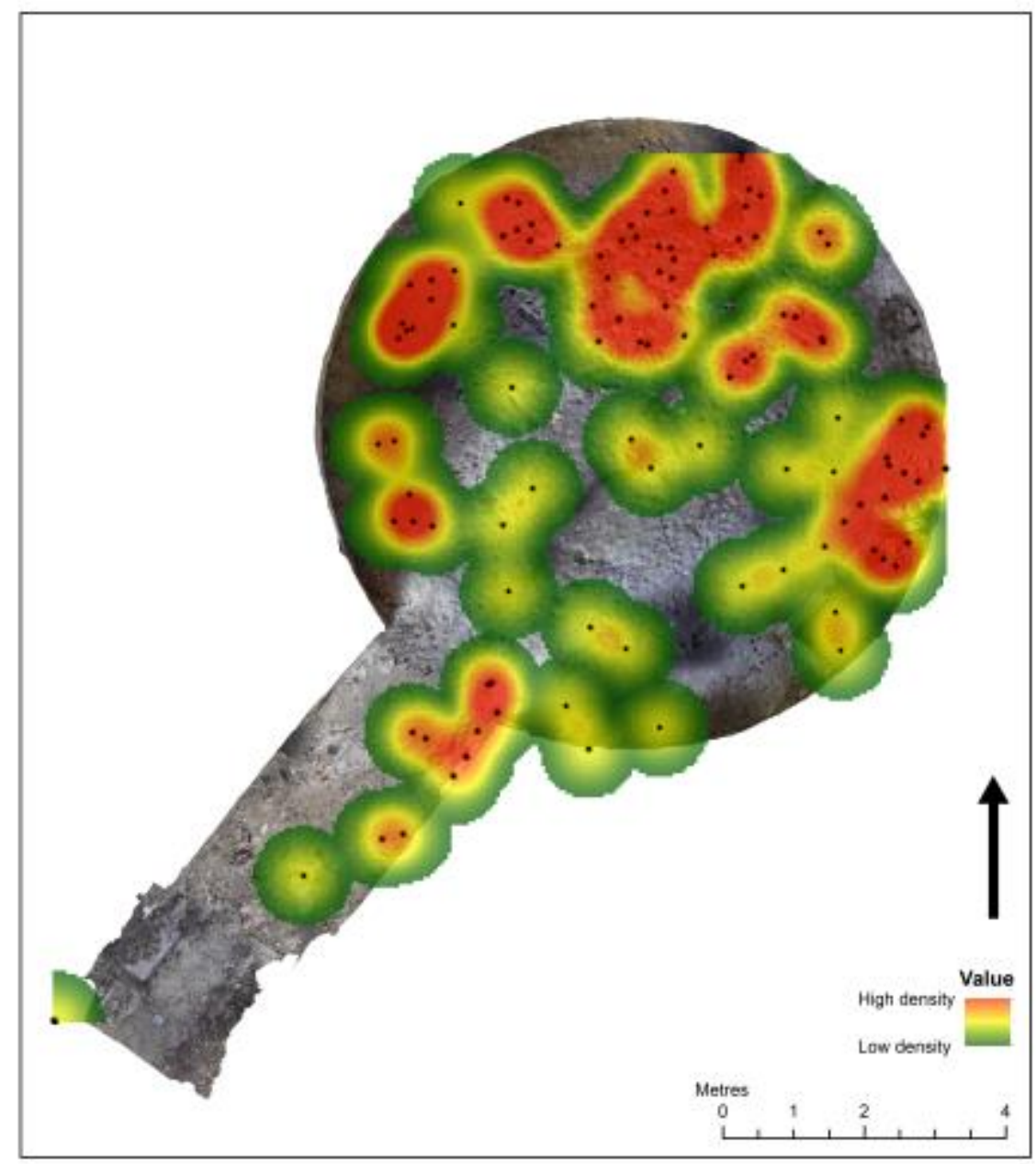


Figure 10: Heat map analysis showing the possible location and distribution of bronze pieces found in the excavation of Tholos IV. Heat map point radii are set to $0.7 \mathrm{~m}$, consistent with the highest assumed level of inaccuracy for any of the point coordinates reconstructed.

Finally, this model is a useful proof-of-concept demonstrating techniques of documentation and digital conservation that could be applied across the wider Messenian landscape. A further tholos tomb lies in the immediate hinterland of the Palace of Nestor c. $1 \mathrm{~km}$ to the south-west. 'Tholos III' excavated by Elizabeth Pierce Blegen and Ida Thallon Hill between April and May 1939, was also published in The Palace of Nestor at Pylos in Western Messenia vol. III. In addition, there is one large tholos tomb down at Voidokilia ('the tomb of Thrasymedes'), excavated by Spyridon Marinatos and then George Korres in the 1950s and 1970s; two tombs at Tragana and one at Koryfasion; and a further tholos tomb came to light during excavations at P.O.T.A.

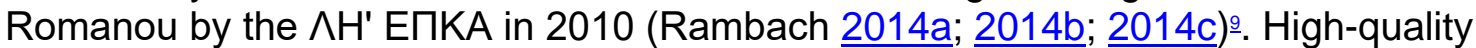
photogrammetry could document digitally the current state of preservation for each of these structures and, where such documentation exists, stratigraphy and finds data could be integrated into a GIS. This would widen our lens of view even further, allowing one to compare and contrast the use of the Messenian tholoi both around and beyond the palace area. This final possibility is purely hypothetical, however, and there are currently no plans for a broader study of the tholos tombs in the Messenia region.

\section{Conclusions}

This case study has demonstrated that the notebooks of Lord William Taylour contain spatial information of a quality high enough to enable projection into a geodatabase with absolute coordinates. This has been made possible by using a methodology that combines the digitalisation of legacy data with newly captured spatial information, obtained through photogrammetry and topographic survey. The methodology has been consistent with the practices employed in the continuing PONEX project, permitting legacy and contemporary data to be read (and analysed) together in the same GIS database. Furthermore, this case study attempts to address a problem faced by a number of similar archaeological sites that have been excavated over a series of generations under different directorships, methodologies, and technologies: how does one bring together legacy data - whose quality and accuracy might be in some senses flawed - with a more rigorous and higher accuracy contemporary dataset?

Discussion has brought to light ways in which this model improves our knowledge not only of the 1953 excavation of Tholos IV but also of the wider landscape of Messenia. Although the authors acknowledge that there is potential for inaccuracy in the digital data, the scale of these inaccuracies is not so great or substantial that the GIS cannot be used to do further substantial research on the legacy excavation and to draw valid conclusions. Moreover, recording a meta-narrative of decisions taken throughout the Tholos IV digitisation project and encoding some of those decisions as layers within the GIS will help equip future researchers with the necessary tools to access more readily both this study and the archival material on which it is based. Fundamentally, then, the Tholos IV GIS serves both as a research tool that allows spatial and stratigraphic information to be integrated with ongoing material studies and a tool for conservation that documents the tholos tomb's present state. Critical, though, is this study for making 
digitally interactive spatial information that was not included in the formal publication of Tholos IV more readily accessible.

Almost seventy years after Lord William Taylour concluded his excavation of Tholos IV at the Palace of Nestor, digital techniques have helped to bring the excavation back to life. Through a close reading of his primary text and through the application of modern digital surveying techniques, we have now taken the first step towards unlocking more of Tholos IV's story.

\section{Acknowledgements}

The rights on the depicted monuments belong to the Hellenic Ministry of Culture and Sports/Archaeological Resources Fund.

The authors would like to thank the Ephorate of Antiquities of Messenia for its enthusiastic support of our research at Pylos, and the Archives of the American School of Classical Studies at Athens for access to primary excavation records. GIS protocols described here were developed between 2018 and 2020 by Michael Loy and Cristiano Putzolu (building on the work of Denitsa Nenova, GIS manager of the PONEX project until 2018, and John Wallrodt, Senior Research Associate in the Department of Classics of the University of Cincinnati). Loy's contribution to the project in 2018 and 2019 was supported jointly by the Arts and Humanities Research Council (AHRC) and Pembroke College Cambridge, award number AH/L503897/1, with further funding for travel made available by the Louise Taft Semple Fund of the Department of Classics of the University of Cincinnati. Cristiano Putzolu is also thanked for assistance in taking the photographs during the photogrammetric survey. Thank you to all the PONEX project supporters. Finally we thank Flint Dibble for introducing us to the EDM software designed by Harold Dibble and Shannon McPherron and making it available to us.

\section{Bibliography}

Allison, P. 2008a 'Dealing with Legacy Data - an introduction', Internet Archaeology 24. https://doi.org/10.11141/ia.24.8

Allison, P. 2008b 'Measuring women's influence on Roman military life: using GIS on published excavation reports from the German frontier', Internet

Archaeology 24. https://doi.org/10.11141/ia.24.5

Blegen, C. 1954 'An early Tholos Tomb in Western Messenia', Hesperia 23(2), 15862. https://doi.org/10.2307/146694

Blegen, C. and Rawson, M. (eds) 1973 The Palace of Nestor at Pylos in Western Messenia. Volume III. Acropolis and Lower Town. Tholoi, Grave Circle, and Chamber Tombs. Discoveries outside the citadel, Princeton: Princeton University Press. 
Clarke, M. 2015 'The digital dilemma: preservation and the digital archaeological record', Advances in Archaeological Practices 3(4), 313-

30. https://doi.org/10.7183/2326-3768.3.4.313

Dibble, H. and McPherron, S. 2010 EDMWIN

2010. https://www.oldstoneage.com/osa/tech/edmwin/

Ellis, S.J.R., Gregory, T.E., Poehler, E.E. and Cole, K.R. 2008 'Integrating legacy data into a new method for studying architecture: a case study from Isthmia, Greece', Internet Archaeology 24. https://doi.org/10.11141/ia.24.3

Esteva, M., Trelogan, J., Rabinowitz, A., Walling, D. and Pipkin, S. 2010 'From site to long-term preservation: a reflexive system to manage and archive digital archaeological data' in IS\&T's Archiving 2010 - Preservation Strategies and Imaging Technologies for Cultural Heritage Institutions and Memory Organizations Final Program and Proceedings (Den Haag, Netherlands 1-4 June 2010) Springfield, VA: Society for Imaging Science \& Technology. 1-6.

González-Tennant, E. 2016 'Recent Directions and Future Developments in Geographic Information Systems for Historical Archaeology', Historical Archaeology, 50(3), 2449. https://doi.org/10.1007/BF03377332

Heaton, P.J. 2003 'Farmsteads and finances in the Finger Lakes: using archival resources in a GIS database', Northeast Historical Archaeology 32, 29-

44. https://doi.org/10.22191/neha/vol32/iss1/4

Katsianis, M., Tsipidis, S. and Kalisperakis, I. 2015 'Enhancing excavation archives using 3D spatial technologies' in C. Papadopoulos, E. Paliou, A. Chrysanthi, E. Kotoula and A. Sarris (eds) Archaeological Research in the Digital Age. Proceedings of the 1st conference on Computer Applications and Quantitative Methods in Archaeology Greek Chapter (CAA-GR), Rethymno, 6-8/3/2014. 46-54. IMS-FORTH.

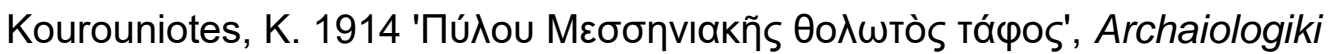
Ephimeris 99-117.

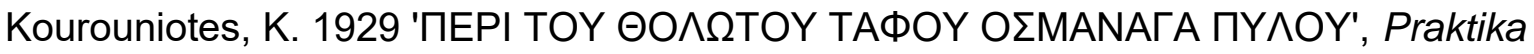
tis en Athinais Archaiologikis Etaireias 1925-1926, 140-1.

Landeschi, G., Apel, J., Lundström, V., Storå, J., Lindgren, S., Dell'Unto, N. 2019 'Reenacting the sequence: combined digital methods to study a prehistoric cave', Archaeological and Anthropological Sciences 11, 2805-

19. https://doi.org/10.1007/s12520-018-0724-5

Marvell, A. 2014 Standard and Guidance for Historic Environment Desk-based Assessment, Reading: Chartered Institute for Archaeologists.

May, K. 2020 'The Matrix: connecting time and space in archaeological stratigraphic records and archives', Internet Archaeology 55. https://doi.org/10.11141/ia.55.8

Mihai, S., Lundberg, J., McFarlane, D. and Chandler, B. 2020 'Pengelly's legacy reconsidered: a GIS approach to spatial analysis of palaeontological and archaeological 
collections from Kents Cavern, England', Proceedings of the Geologists'

Association 121, 319-25. https://doi.org/10.1016/j.pgeola.2010.07.003

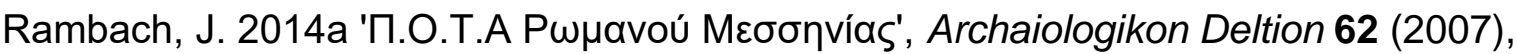
351-4.

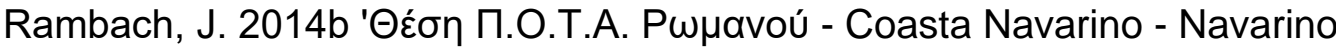
Dunes', Archaiologikon Deltion 63 (2008), 399-403.

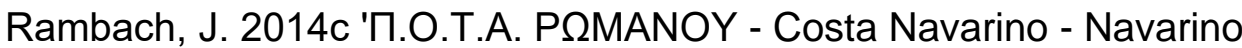
Dunes', Archaiologikon Deltion 64 (2009), 361-4.

Richards-Rissetto, H. and Landau, K. 2019 Digitally-Mediated Practices of Geospatial Archaeological Data: Transformation, Integration, \& Interpretation, Anthropology Faculty Publications 163. https://doi.org/10.5334/jcaa.30

Schepartz, L.A., Miller-Antonio, S. and Murphy, J.M.A. 2009 'Differential health among the Mycenaeans of Messenia: status, sex, and dental health at Pylos' in L.A. Schepartz, S.C. Fox and C. Bourbou (eds) New Directions in the Skeletal Biology of Greece, Athens: The American School of Classical Studies at Athens. 155-74.

Schepartz, L.A., Papathanasiou, A., Miller-Antonio, S., Stocker, S.R., Davis, J.L., Murphy, J.M.A., Malapani, E. and Richards, M. 2011 'No seat at the table? Mycenaean women's diet and health in Pylos, Greece' in L.A. Shepartz (ed) Anthropology à La Carte: The Evolution and Diversity of Human Diet, San Diego. 359-74.

Schepartz, L.A., Stocker, S.R., Davis, J.L., Papathanasiou, A., Miller-Antonio, S., Murphy, J.M.A., Richards, M.P. and Malapani, E. 2017 'Mycenaean hierarchy and gender roles: diet and health inequalities in Late Bronze Age Pylos, Greece' in H. Klaus, A. Harvey and M.N. Cohen (eds Bones of Complexity: Bioarchaeological Case Studies of Social Organization and Skeletal Biology, University Press of Florida. 14172. https://doi.org/10.2307/i.ctvx07bk4.12

Steele, L. and Frey, J. 2018 'Using GIS to Explore Legacy Spatial Data at Isthmia', poster presented at the Archaeological Institute of America Annual Meeting, Boston, Massachusetts (Boston Marriott: Copley Place), 4-7 January 2018. https://www.researchgate.net/publication/324524927 Using GIS to Explore Leg acy Spatial Data at Isthmia

Taylour, W. 1973 'Tholos Tomb IV' in C. Blegen and M. Rawson (eds) The Palace of Nestor at Pylos in Western Messenia. Volume III. Acropolis and Lower Town. Tholoi, Grave Circle, and Chamber Tombs. Discoveries outside the citadel, Princeton: Princeton University Press. 95-134.

Vassallo, V. 2019 'Re-examining a 20th century archaeological excavation in 3D GIS. The Ayia Irini (Cyprus) sanctuary and its finds', International Conference on Cultural Heritage and New Technologies, CHNT 24. PDF

Wallace, C.A.B. 2017 'Retrospective photogrammetry in Greek archaeology', Studies in Digital Heritage 1(2), 607-26. https://doi.org/10.14434/sdh.v1i2.23251 
Witcher, R. 2008 '(Re)surveying Mediterranean Rural Landscapes: GIS and legacy survey data', Internet Archaeology 24. https://doi.org/10.11141/ia.24.2

Woywitka, R. and Beaudoin, A. 2009 'Legacy databases and GIS: a discussion of the issues illustrated by a case study of archaeological site data from southeast Alberta, Canada', The Canadian Geographer 53(4), 462-72. https://doi.org/10.1111/1.1541$\underline{0064.2009 .00282 . x}$

Wylie, A. 2017 'How archaeological evidence bites back: strategies for putting old data to work in new ways', Science, Technology, \& Human Values 42(2), 203-

25. https://doi.org/10.1177/0162243916671200 